\title{
Percepción de las camaristas de hoteles en Cancún sobre su situación laboral: una perspectiva cultural del género en turismo
}

\section{Cancun hotel Chambermaids and their perceptions of their own working conditions: a cultural perspective of gender in tourism}

Antonia Balbuena Vázquez (iD, Universidad Nacional Autónoma de México, México abalvaz@yahoo.es

Álvaro López López (iD, Universidad Nacional Autónoma de México, México lopuslopez@igg.unam.mx

\section{RESUMEN}

Este estudio aborda desde una perspectiva cultural del género, las condiciones laborales de las camaristas de hoteles en Cancún, México. Para ilustrar este tema se entrevistaron a profundidad a diez empleadas que trabajaron o trabajan en la zona hotelera de este famoso centro turístico. Se procesaron los datos en el software cualitativo Atlas.ti y ello permitió saber que su limitada educación formal, bajo nivel económico y condición de migración, son factores que inciden en que soporten condiciones laborales que, aunque pudieran ser extenuantes, son percibidas por ellas como positivas, frente a las dificultades para su inserción en el mercado laboral regional. En general todas estas trabajadoras perciben salarios bajos en el sector hotelero, sin embargo, tienen como incentivo principal -a fin de mantenerse en esta profesión- la expectativa de obtener propinas.

Palabras clave: camaristas/camareras de piso; género; hoteles; turismo; Cancún (México).

\section{ABSTRACT}

This study addresses the perceptions of chambermaids in Cancun, Mexico, of their own working conditions, from the cultural perspective of gender. To approach this subject, 10 women who work or have worked in the hotel area of this famous tourist destination were interviewed. The data were processed with Atlas.ti qualitative software. The results show that the willingness of these women to withstand harsh working conditions for many exhausting hours, and their tendency to perceive them as acceptable, is a function of their limited formal education, low socioeconomic level, and migratory status, all of which make it difficult for them to compete 
in the job market. Although these women receive low wages in the hospitality sector, they see the prospect of tips as an incentive.

Keywords: chambermaids; gender; hotels; tourism; Cancun.

\section{INTRODUCCIÓN}

Cancún, ubicado en el mar Caribe mexicano, es uno de los núcleos turísticos litorales más famosos del mundo (Sedetur, 2017). Esta ciudad se creó literalmente de la nada. Resultado de un proyecto gubernamental concebido para el turista, en la realidad socioeconómica mexicana se llegó a la generación de dos espacios, que aunque continuos, están bien diferenciados (Mapa 1): la zona hotelera y la denominada ciudad de Cancún, donde habitan los residentes y trabajadores que se desplazan a la zona turística a prestar sus servicios (López, Cukier y Sánchez 2006; Castillo y Villar, 2011; Arroyo, López, Segrado, Serrano, Frausto, 2015). Desde su origen Cancún es un enclave de la economía internacional con pocos beneficios para la sociedad regional (García, 1979).

\section{Mapa 1. Localización de Cancún}
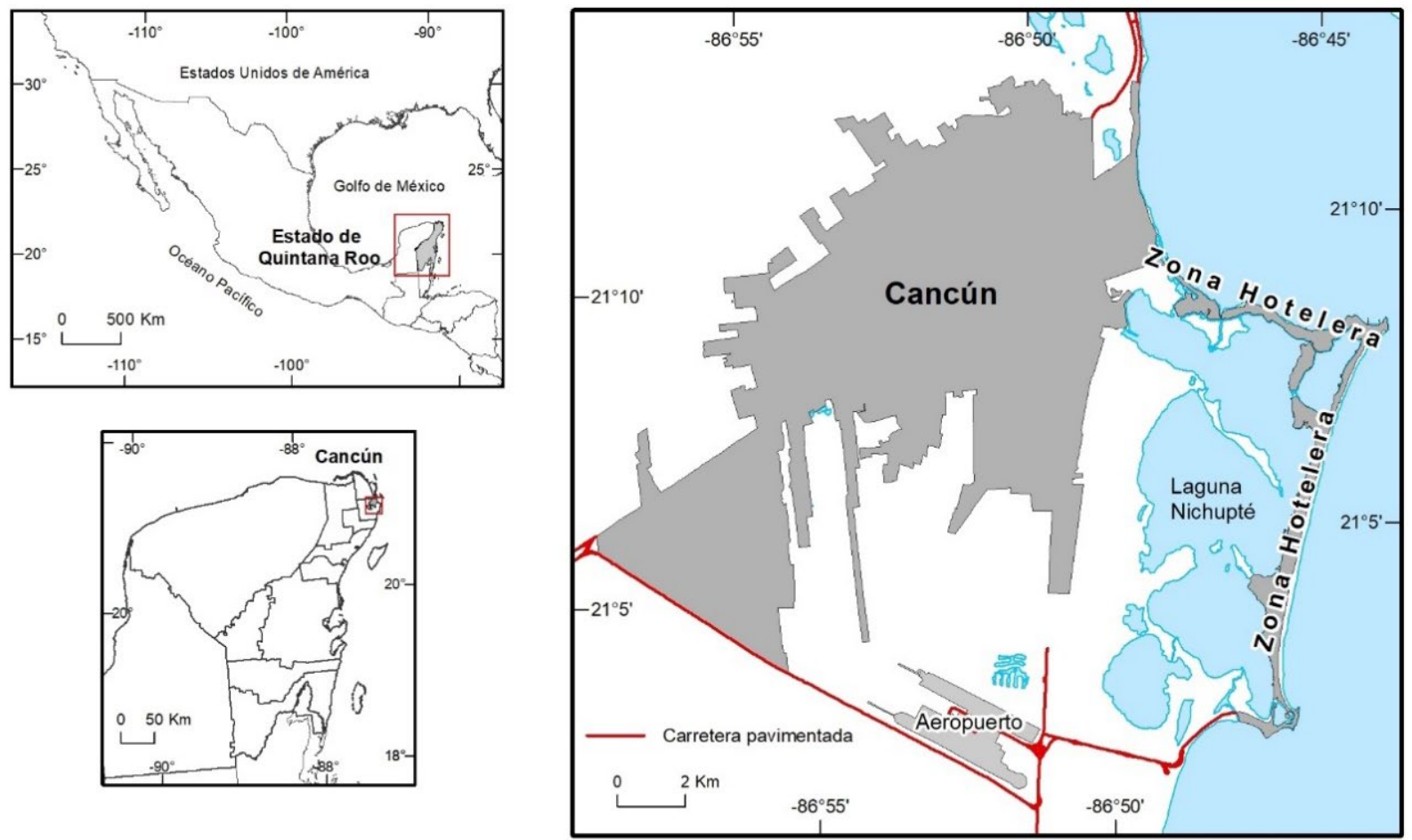

Fuente: Elaborado por María de Lourdes Godínez Calderón, 2019.

El crecimiento intensivo y expansivo de Cancún desde sus inicios, en 1975, atrajo un importante núcleo de población inmigrante de otros estados de México, interesado en las ofertas de empleo del sector turístico. Sin embargo, la gran mayoría de los empleos ofertados han sido poco cualificados y temporales (Oehmichen, 2010). Las mujeres que laboran en 
el turismo en la región de Cancún se han empleado sobre todo como ayudantes de cocina, camaristas, supervisoras o recepcionistas, lo que refuerza roles tradicionales de género, con desventajas para ellas (Ferguson, 2011).

A pesar de que en algunas regiones del mundo ya son relevantes los estudios sobre la desigualdad laboral en contextos turísticos, aún son limitadas las investigaciones que abordan el trabajo de las mujeres bajo una perspectiva cultural de género. Las desigualdades estructurales del empleo turístico suelen estar ocultas y normalizadas, como ocurre en el caso de Cancún (Ferguson, 2010; Vizcaino, Serrano-Barquín, Cruz y Pastor-Alfonso, 2014; Serrano, et al., 2017).

En el marco mexicano no se han encontrado estudios que aborden el empleo de mujeres en las actividades de limpieza en ámbitos turísticos, de modo que la presente investigación es uno de los primeros abordajes en este sentido. No obstante, es importante reconocer que este estudio tiene como antecedente investigativo principal los estudios de Cañada (2015 y 2016), sobre las condiciones laborales de las camaristas empleadas en destinos turísticos en España, pues son referentes teóricos y empíricos litorales existentes más cercanos a la situación de Cancún. Por otro lado, esta investigación también se ha basado en otros estudios que previamente a Cañada analizaron la situación de las limpiadoras de hoteles en otros lugares (Hunter y Watson, 2006; Onsøyen et al., 2009; Kensbock, et al., 2013; Hsieh, Apostolopoulos y Sönmez, 2013).

En este contexto, el objetivo de esta investigación es exponer la percepción que las camaristas que laboran en el centro turístico de Cancún tienen acerca de su empleo, en la búsqueda de revelar situaciones normalizadas de inequidad. Para lograr este fin, y a partir de una metodología cualitativa, enfocada a conocer en amplitud las valoraciones de los sujetos de estudio, se privilegió ahondar la relación de comunicación con las camaristas; así, se hicieron diez entrevistas a profundidad a camaristas: nueve a mujeres y una a un hombre. El hecho de que las mujeres predominen en la limpieza de habitaciones de hoteles en Cancún y de que el único varón entrevistado se hubiera referido consistentemente como "nosotras" al hablar en plural, permite, en lo sucesivo, denominar en femenino al conjunto de personas entrevistadas.

El artículo está organizado en los siguientes apartados: I. La introducción. II. El marco teórico, abocado a entender cómo se construye el género desde una perspectiva cultural, respecto de los roles impuestos socialmente, la importancia de abordar al turismo desde la perspectiva de género y las condiciones laborales que viven las camaristas. III. La metodología, de orden cualitativo a partir de entrevistas semiestructuradas y a profundidad, procesadas en el software ATLAS. ti. IV. Los resultados obtenidos, expresados en la red semántica donde se relacionan las categorías clave: el perfil y contexto de procedencia de las camaristas, las condiciones laborales y organizativas del hotel, la relación con los jefes, los aspectos de salud y su percepción sobre su trabajo, así como la relación que se genera con los turistas. V. Finalmente, se presentan algunas conclusiones. 


\section{MARCO TEÓRICO}

\subsection{Trabajo y turismo: la importancia del género}

El sexo y el género son dos conceptos que tienden a confundirse y utilizarse como sinónimos. El sexo hace referencia a las características biológicas, anatómicas, fisiológicas y genéticas que distinguen a machos o hembras (Pacheco, 2012; Gutiérrez y Limas, 2008; Escudero et al., 2017). Sin embargo, el género se refiere a la existencia de un conjunto de normas sociales que definen a lo femenino, distinguido de lo masculino, o viceversa (Lamas, 2000; Escudero et al., 2017); es una construcción cultural que determina la asignación de roles que corresponden a cada uno de los sexos en cada sociedad y en cada época histórica, establecidos como normas que deben cumplir hombres y mujeres, tanto en el ámbito privado como el público (Cotelo, Herrera y Alarcón, 2016). También este término conlleva el cumplimiento de ciertos estereotipos vinculados con las estructuras del poder (Araiza, 2004). De esta manera, aunque cada sociedad define el modo específico de ser mujer, predominan los modelos en los que vincula lo femenino con la maternidad, la crianza de menores, el cuidado de mayores y las labores del hogar (cocinar, limpiar, cuidar).

Estos procesos de construcción sociocultural de lo que es lo femenino y lo masculino, son condicionamientos que se van asumiendo desde el nacimiento, tanto explícita como tácitamente, y quedan establecidas a partir de la vestimenta, los arreglos y poses corporales, según los patrones sociales de masculinidad y feminidad (Martín, 2012). La construcción de la identidad de género implica que se formen discursos, concepciones e ideas sobre los roles sociales identitarios, con lo que se asignan determinados trabajos o tareas que se consideran "correctos" para los hombres y las mujeres, de acuerdo con su rol social de género e incluso se determina lo que "debe ser una mujer" o "debe ser un hombre" (Serrano, et al., 2017).

Históricamente, las mujeres han tenido la obligación de atender el hogar y a las personas de su entorno inmediato, y con su incorporación al mercado laboral reproducen estas prácticas domésticas en trabajos de cuidados, de atención a las personas, de administración, entre otras, que luego, han pasado a ser remuneradas. Las relaciones de trabajo ahondaron las desigualdades de género, las cuales tienen una importante incidencia en las experiencias de las trabajadoras. Por tanto, los estudios de género desde su construcción cultural proveen de las herramientas necesarias para cuestionar la naturalización de las identidades femeninas y masculinas, y que han favorecido la construcción sociohistórica de comportamientos y espacios de trabajo para cada género (Queirolo, 2004; Garazi, 2014).

En los estudios de género y turismo, desde una perspectiva sociocultural, se ha observado una segregación de género por áreas, fundamentada en la idea de que hay trabajos "de hombres» y trabajos "de mujeres», y que éstos últimos valen menos a raíz del género (Fernández y Martínez, 2010). Las mujeres en el sector turístico no se encuentran en una situación de igualdad: la mayoría de los empleos en los hoteles están prescritos patriarcalmente y, ciertas labores son ampliamente asumidas por las mujeres por reflejar esas "actitudes inherentes" que poseen: la limpieza y la cocina (Purcell, 1996; Sparrer, 2003; Huete, et al., 2016); 
en cambio, las principales ocupaciones de los hombres son las de meseros, jardineros, mantenimiento, entre otros.

Los trabajos "de mujeres" también se hacen extensivos a muchos varones diverso-sexuales (particularmente algunos que se muestran abiertamente como afeminados), que socialmente y con frecuencia quedan circunscritos a tareas consideradas femeninas. Este grupo de varones diverso-sexuales que se sienten discriminados por otros hombres en los trabajos que se consideran "de hombres" se sienten más incómodos en aquellos empleos altamente masculinizados, en donde además de exponerse a la discriminación, suelen ocupar posiciones suplementarias, dados los prejuicios hacia lo femenino (Cáceres y Valcuende, 2014).

El control patriarcal no se muestra sólo en el tipo de trabajo, como se indicaba anteriormente, sino también en la remuneración, en donde las mujeres suelen ocupar los trabajos más precarizados, los niveles más altos de flexibilidad y los salarios más bajos, mediante figuras contractuales más inestables (Ferguson, 2010; Ferguson y Moreno, 2015; Albarracín y Castellanos, 2013). El sector turístico se convierte así en un reproductor de los roles tradicionalmente asociados a las mujeres, que las someten a puestos de menos cualificación y valoración de los hoteles, meramente operativos, lo que refuerza la división del trabajo (Sinclair, 1997; Li y Wang, 2001; Munshi, 2006; McKenzie, 2007; Caamaño, 2010; Fernández y Martínez, 2010; Sigüenza, 2011; Díaz, 2013; Díaz, Verján y Castrejón, 2014; Heather, 2018; García, Galante y Poveda, 2018).

Así, en los empleos u ocupaciones con niveles inferiores, con pocas oportunidades de desarrollo profesional, desvalorizados y mal pagados, suelen estar confinadas las mujeres, para quienes además es común que tengan mucha dificultad o imposibilidad de ascender en el escalafón de los puestos de trabajo: a esto se le ha denominado "suelo pegajoso" (Torns y Recio, 2012). Otro concepto que expresa la dificultad que las mujeres tienen para llegar a los puestos medios o altos es el de "techo de cristal", que alude a las barreras que este género tiene para ocupar este tipo de empleos, caracterizados por la gran responsabilidad que implica y que suelen estar reservados a hombres (Guil, 2008; Segovia, 2013; Huete, et al., 2016).

\subsection{Las camareras de piso o camaristas}

A las trabajadoras que limpian las habitaciones de los hoteles de diferentes lugares del mundo se les llama "criadas", "amas de llaves", "asistentes de habitación", "mucamas" y "camareras de piso", pero en México son "camaristas".

El área de limpieza en los hoteles es operada básicamente por mujeres, con tres figuras centrales: las amas de llaves, las supervisoras y las camaristas. Tanto las primeras como las segundas están encargadas de inspeccionar y coordinar el trabajo de las personas a su cargo, elaborar los horarios, gestionar las incidencias y los servicios de lavandería y materiales a necesitar para la realización del trabajo. Las camaristas, tanto en el ámbito latinoamericano como anglosajón, se encargan de limpiar los cuartos bajo estándares de calidad establecidos por cada hotel y, así, contribuir a la satisfacción general de los clientes (Hsieh, Apostolopoulos y Sönmez, 2013). 
En el ámbito turístico mundial, las camaristas suelen ser trabajadoras inmigrantes y tener una educación mínima (Albarracín y Castellanos, 2013), características que también describen el contexto mexicano. Además, se ha desvelado que las condiciones laborales de las camaristas en destinos turísticos anglosajones, así como en España se han ido degradando: bajos salarios, contratos temporales, parciales o por horas, incremento de la carga de trabajo, entre otras (Cañada, 2016). La contratación flexible, así como la externalización (outsourcing) de una parte de la plantilla es causada por las empresas hoteleras que han favorecido estos mecanismos, las cuales, justifican tales acciones por la estacionalidad del turismo, mientras que su empleo se precariza (Seifert y Messing, 2006; Liladrie, 2010; Cañada, 2016, 2018 y 2019).

La problemática laboral es particularmente desfavorable para las camaristas en las temporadas altas del turismo, pues la mayor demanda de trabajo no se resuelve con la mayor contratación de trabajadoras, sino haciendo más intensiva su carga de trabajo e incrementado la cantidad de horas de servicio, y esto puede ser aún mayor con la ausencia de otras compañeras (Real-Pérez, et al., 2011). Esto ocasiona que estas mujeres regresen tarde y muy cansadas a sus casas, haciéndoles dificultoso conciliar su vida laboral con la familiar (McNamara, et. al., 2011; Cañada, 2016).

Además, el tiempo trabajado fuera de su horario laboral no se considera como "horas extras", si acaso sólo reciben un poco más de dinero (Triguero, 2017). Como ejemplo, a partir de la poca literatura disponible, se refiere que en países como España las camareras de piso en plantilla han de limpiar entre 12 y 16 habitaciones por día o turno, sin embargo, a través de las agencias o empresas multiservicio de subcontratación u outsourcing se les llegan a imponer de 20 a 30 habitaciones (Triguero, 2017). Esta tarea asignada por jornada es obligatoria y ha de ser finalizada dentro del horario establecido, o bien, continuar trabajando hasta acabar (Cañada, 2018 y 2019); para ello, recurren a diversas técnicas: trabajar más deprisa, evitar los descansos y saltarse la hora del almuerzo, a fin de evitar represalias y demostrar sus capacidades (Hsieh, Apostolopoulos y Sönmez, 2016; Seifert y Messing, 2006).

En general, una habitación es limpiada en menos de 30 minutos, pero pueden ser aún mayores las circunstancias adversas de las camaristas: a) cuando los huéspedes se retiran después de la hora estipulada -aunque la empresa les cobre el exceso de tiempo a los clientes- la trabajadora debe hacer la habitación tardíamente sin ninguna remuneración extra; b) cuando las habitaciones están más sucias de lo normal, por comportamientos inusuales de personas como spring breakers o "turistas de borrachera", deben esmerarse más, lo que redunda en un sobreesfuerzo físico y en el retraso de su horario de salida y proceso de trabajo (Hsieh, Apostolopoulos y Sönmez, 2013; Cañada, 2018).

En buena medida, la carga de trabajo en la limpieza de habitaciones de hoteles tiene que ver con el aumento de las exigencias del turista (Lockwood y Guerrier, 1989), y dado que los hoteles compiten con otras empresas para lograr mayor fidelidad con sus clientes, se incrementa la carga de trabajo en las camaristas, con daños importantes a su salud (Cañada, 2018). La mayoría de estas trabajadoras presentan patologías por diversas causas: problemas de espalda, dolor generalizado, estrés y otros trastornos psicológicos, lo que da lugar a que 
casi ninguna de ellas llegue a su retiro o jubilación en buenas condiciones físicas (Scherzer, Rugulies, y Krause, 2005; Premji y Krause, 2010; Hsieh et al., 2014, 2016; Oxfam, 2017; Cañada, 2019). Además, si alguna camarista solicita un permiso de ausencia por enfermedad, es alta la probabilidad de que se le despedida, pues es tal la demanda de empleo que resulta rentable despedir a una trabajadora (Asociación las Kellys, 2017).

Lockwood y Guerrier (1989) han documentado que en el trabajo de limpieza hotelero no existen días festivos para las camaristas y que es común que pierdan sus días libres, lo que propicia que la duración media para soportar este empleo sea de seis semanas. Esta circunstancia, además de los contratos por horas y la rotación continua de personal, limita su organización para luchar por mejores condiciones laborales (Puech, 2007).

Las camaristas no perciben en el sindicato de la empresa un apoyo a sus circunstancias o problemas laborales (Asociación las Kellys, 2017), es decir, no se sienten protegidas ni por el sindicato ni por la mayoría de sus supervisores o jefes más inmediatos, más aún, padecen de ellos un control negativo y el dictado de unas normas despóticas y arbitrarias; así, aceptan una subordinación que las infravalora y que las lleva a soportar faltas de respeto, por miedo a ser despedidas.

Además, entrar solas a espacios privados, donde habitan temporalmente las o los clientes, las posiciona en un marco de riesgo y vulnerabilidad frente al acoso sexual, insinuaciones o conductas amenazadoras por parte de los turistas, que son problemas casi normalizados y poco estudiados (Hunter y Watson, 2006; Oxfam, 2017; Moreno y Cañada, 2018). Ante esta situación, las camaristas no denuncian por tres razones: no existen protocolos de actuación en el hotel o se omiten, pues se asume que "el cliente siempre tiene la razón"; miedo a ser despedidas y, por último, no se ve la gravedad del asunto porque se considera inherente a su trabajo (Hunter y Watson, 2006).

\section{METODOLOGÍA}

\subsection{Método e instrumento}

La presente es una investigación cualitativa de aproximación al contexto de las camaristas, sus experiencias y su cotidianidad laboral, no sólo para entender sus condiciones laborales, sino para revelar su percepción al respecto (Zamora, Barril y Benavides, 2010). El instrumento utilizado para obtener la información deseada fue la entrevista semi-estructurada en profundidad. En este punto es conveniente señalar que durante el desarrollo del trabajo de campo se observó gran reticencia de las camaristas para aceptar ser entrevistadas y, una vez implicadas en la entrevista, mostraban temor de hablar y exponer con libertad sus puntos de vista. En Cancún -y en general en México- las camaristas no están sindicalizadas y, por lo tanto, pueden ser despedidas con facilidad, de modo que se sentían vulnerables y eso implicó tener diferentes reuniones con ellas, antes de que los/las autores/as de este artículo reconocieran que habían expresado los asuntos relevantes y de interés en la investigación.

Si bien este estudio no se basó en una muestra estadística, en un principio se tenía el interés de entrevistar a un número significativamente mayor de camaristas, sin embargo, al 
ver las dificultades en el desarrollo del trabajo de campo se consideró entrevistar a diez informantes, a fin de poder ampliar el número de sesiones con ellas, incrementar su confianza y, en consecuencia, elevar la calidad de la información, en el entendido de que la realidad y el conocimiento son construidos subjetivamente y de que se deben hacer aflorar y explorar los puntos de vista de las personas interrogadas (McDowell, 2010; Mogensen, Mayer, Breiting y Varga, 2007).

Se tuvieron entre dos y tres sesiones que sumaron entre tres y cinco horas de conversación total con cada entrevistada y durante el período que duró el trabajo de campo, -diciembre del 2018 a marzo de 2019- se tuvo una convivencia amplia a fin de incrementar la empatía con las trabajadoras. Las camaristas habían trabajado o trabajan en ese momento en la zona hotelera de Cancún (Mapa 1). En tanto que el interés de este estudio fue el de revelar las condiciones del empleo turístico femenino de las camaristas, a través de experiencias subjetivas, se tomó como punto de partida los estudios de Cañada (2015, 2016 y 2018), que le condujo a comprender los patrones de las camaristas que él investigó. Así, se pudo evidenciar, desde las primeras entrevistas realizadas para este artículo, que las camaristas tenían respuestas recurrentes, de modo que se llegó pronto al punto de saturación.

La primera entrevistada se conoció a través de un informante clave de la Universidad del Caribe (Cancún) y el resto surgió mediante el muestreo de bola de nieve, aunque varias de las invitadas decidían no participar al saber que debían platicar de sus experiencias en los hoteles en los que trabajaban; al final las camaristas lograron sentirse cómodas en el anonimato, al corroborar en el curso de las pláticas que el uso de la información sólo tenía fines académicos y de que se utilizarían seudónimos para referirlas (Medeiros de Araujo y Bramwell, 1999; Reed et al., 2006; Hubacek et al., 2006).

Cada entrevista consistió en una conversación informal, siguiendo una guía de los temas clave: condiciones laborales, trayectoria laboral, relaciones con los jefes, el trato del turista, salud laboral y percepción del trabajo como camarista; se efectuaron en los lugares de mayor conveniencia a las camaristas, sobre todo sus casas y cafeterías. Con la conformidad de ellas, las entrevistas fueron grabadas en voz y posteriormente transcritas y editadas para eliminar muletillas y repeticiones; también se organizó la información de manera temática y acorde con los intereses de la investigación, pero siempre con respeto a sus ideas centrales.

Puesto que este artículo es el primero que analiza el trabajo de las camaristas en un centro turístico mexicano, la guía de la entrevista tomó como base los trabajos de Cañada (2015, 2019), pero en consideración con la realidad laboral en hoteles del Caribe mexicano. Así, los tópicos más representativos que se exploraron fueron: 1. Perfil general de las trabajadoras. 2. Condiciones laborales y organizativas entre las trabajadoras y el hotel. 3. Las relaciones establecidas entre los jefes y ellas. 4. La percepción que las camaristas tienen de su trabajo en términos de justicia laboral y vínculos sociales. 5 . El contexto de procedencia, es decir, la trayectoria laboral que les condujo a este trabajo. 6 . La relación establecida entre los huéspedes y las camaristas. 
Los textos obtenidos fueron analizados utilizando la herramienta informática ATLAS. ti. Se encontró que el ATLAS. ti era adecuado en el procesamiento de datos, su codificación, organización y estructuración de información, según el sistema de categorías utilizado (Sabariego, Vilà y Sandín, 2014), al tiempo que permitió extraer citas textuales relevantes. También se elaboró una tabla con los tres códigos más citados de todas las entrevistas, los cuales fueron: jefe, huésped y propina. También se creó una red semántica o network, es decir, se representaron gráficamente, a modo de mapa conceptual, las categorías clave y sus relaciones.

\section{ANÁLISIS DE RESULTADOS}

\subsection{Número de citas y red semántica}

Con el software Atlas.ti se obtuvo una tabla con los tres códigos más citados y de mayor peso en la percepción que las camaristas tienen de su trabajo. En primer lugar, el código "jefa/e" con 42 citas, luego la palabra "huésped" con 29 menciones y por último "propina" con 25 señalamientos, tal como se analizará más adelante (Tabla 1). De esta manera, estas palabras fueron atendidas especialmente en todos los rubros del análisis posterior.

Tabla 1. Número de citas por código

\begin{tabular}{|l|c|}
\hline \multicolumn{1}{|c|}{ Código } & $\begin{array}{c}\text { No de citas por } \\
\text { código }\end{array}$ \\
\hline Jefe & 42 \\
\hline Huésped & 29 \\
\hline Propina & 25 \\
\hline
\end{tabular}

Fuente: Elaboración propia con base en trabajo de campo 2018 y 2019.

Dentro del propio Atlas.ti se generó una red semántica de códigos o un mapa conceptual que ayudó a representar gráficamente las relaciones de los códigos y/o categorías que ayudaron a conectar las percepciones (Grafica 1). Como se puede observar, tienen puntos centrales las categorías "Condiciones laborales", "Percepción" y "Propina". Estas tres palabras clave engloban y se relacionan con el resto de las categorías que se usaron para sintetizar la información y, al mismo tiempo, entre ellas mismas se conectan: la percepción de las camaristas se relaciona con las condiciones laborales y, a su vez, con la propina. 
Gráfica 1. Red semántica de códigos

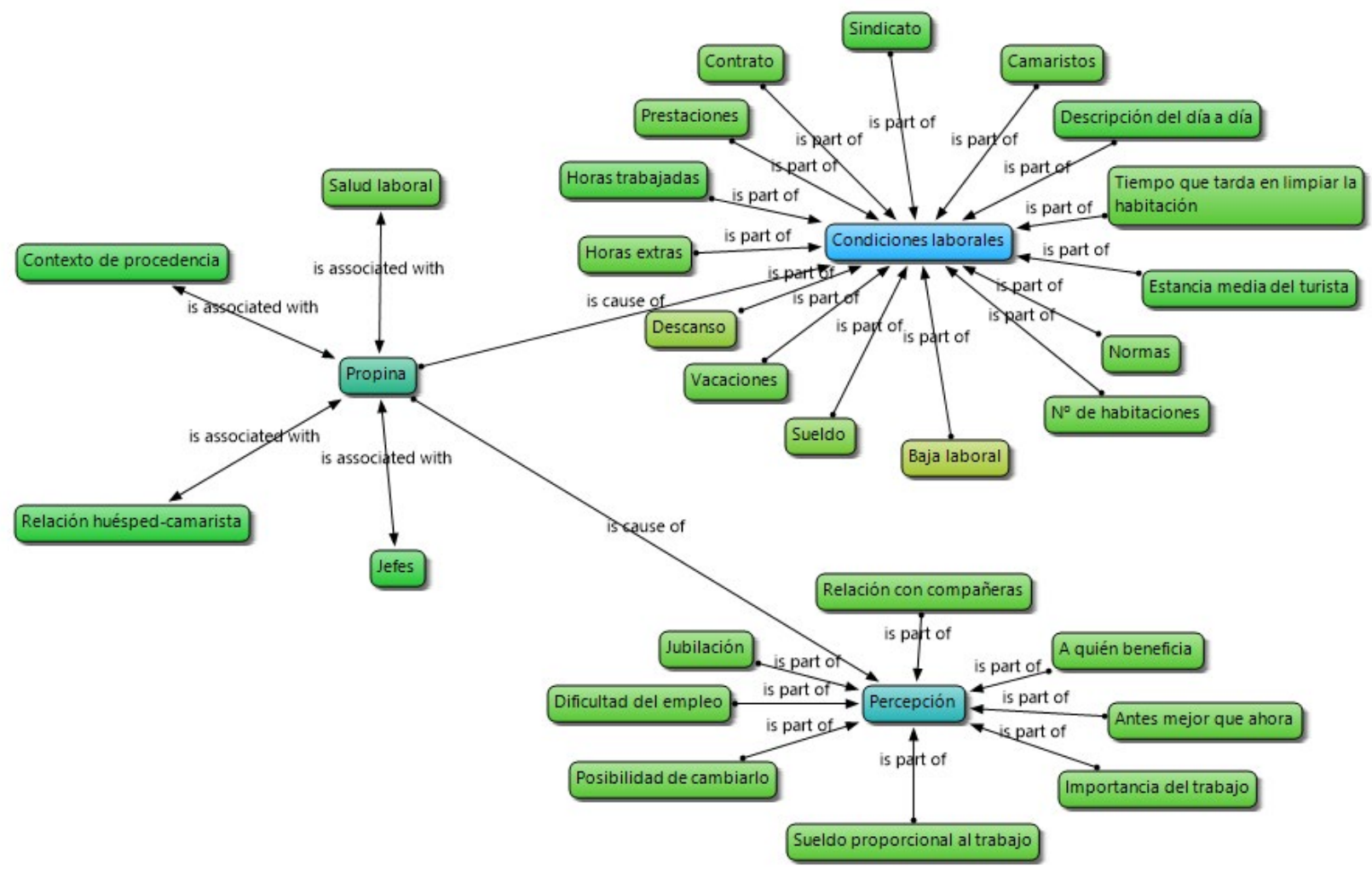

Fuente: Elaboración propia con base en trabajo de campo 2018 y 2019.

\subsection{Perfil general de las trabajadoras y su contexto de procedencia}

Fueron entrevistadas nueve mujeres y un hombre; cinco ya habían dejado el trabajo de limpieza en hoteles y el resto continuaba ejerciéndolo, y sólo una de ellas había conseguido ser supervisora. Todas vivían en Cancún y habían trabajado o trabajan en la zona hotelera (Mapa 1); cinco eran casadas, dos solteras, dos separadas o divorciadas y una viuda. Cuatro de ellas tenían entre 41 y 50 años, tres entre 51 y 60 años, dos menores de 40 años y una de más de 61 años; todas tenían hijos -como media dos- y la mayoría aún tenían hijos dependientes a su cargo.

La mayoría había cursado estudios primarios; todas eran inmigrantes procedentes de entidades mexicanas cercanas a Quintana Roo (el estado donde se sitúa Cancún) como Tabasco (cuatro), Campeche (dos), Chiapas (dos), Guerrero (una) y Yucatán (una). Todos son estados del sur de México (Mapa 2). Desde el surgimiento de Cancún, su turismo se ha convertido en una de las principales fuentes de ingresos para todos los estados señalados, mismos que corresponden con las entidades más marginadas de México (CONAPO, 2015). Esta situación beneficia ampliamente a los empresarios hoteleros de Cancún, pues disponen de un ejército laboral muy amplio. 
Mapa 2. Estados de procedencia de las camaristas
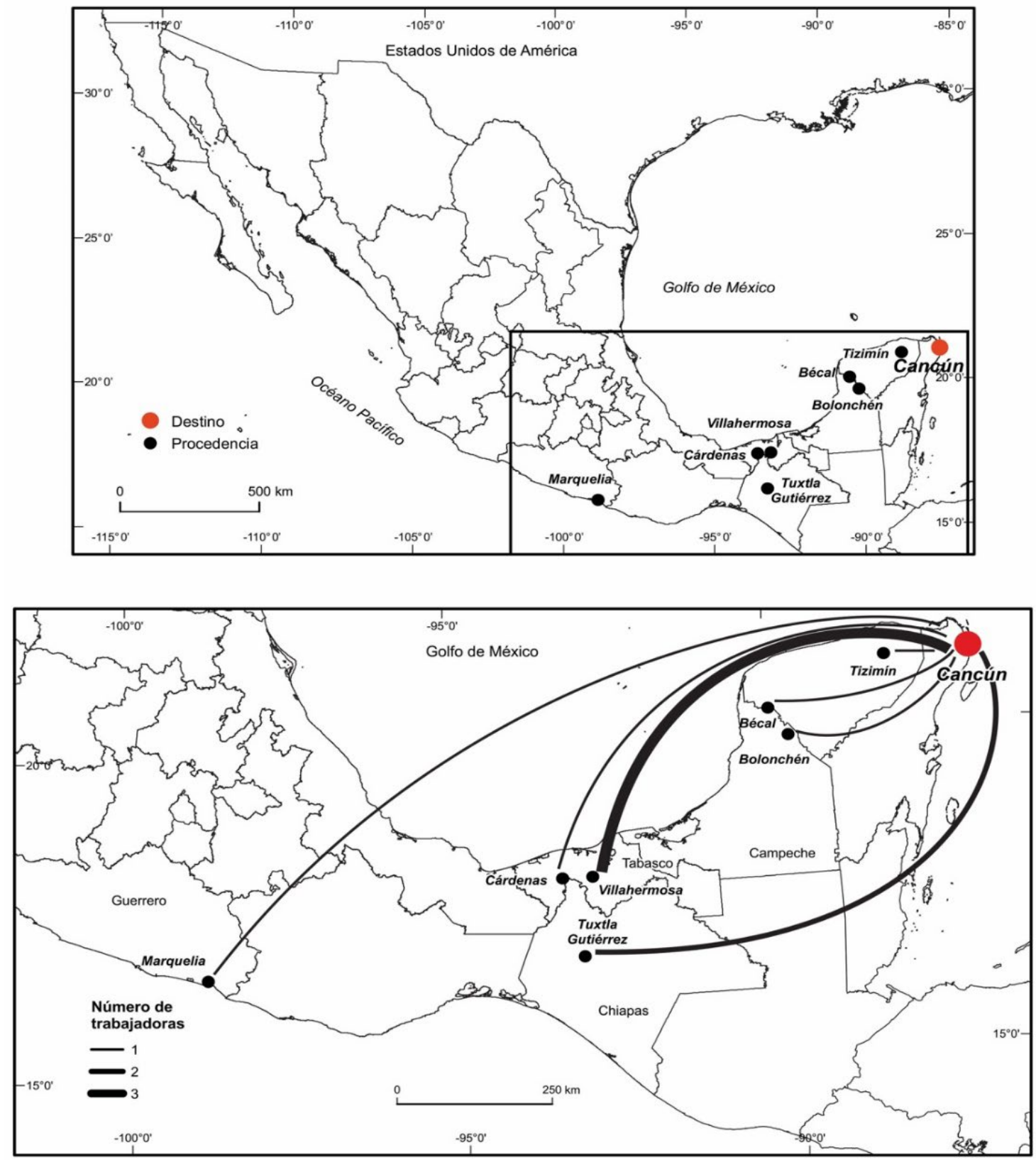

Fuente: Elaborado por María de Lourdes Godínez Calderón, 2019, con base en trabajo de campo 2018 y 2019.

Por sus propias condiciones de marginación, casi todas las camaristas comenzaron a trabajar en la limpieza desde su primer empleo, ya sea en casas, como aprendices de camaristas o en la limpieza de áreas públicas en hoteles. Es relevante señalar que la procedencia rural de mujeres como Raquel, les supone una confrontación social y laboral muy fuerte cuando llegan a un complejo turístico como Cancún. Raquel, por ejemplo, en su tierra natal, Campeche, se dedicó a la siembra y cuando llegó a Cancún comenzó a trabajar en los hoteles, labor que dejó al poco tiempo de probarlo pues le pareció muy duro, "la milpa era más suave, al menos la cosecha y la recolección de este cultivo se realiza al ritmo de cada uno, muy al contrario del 
acelerado ritmo que se impone limpiando habitaciones". No obstante, viendo que sacaba un dinero extra con las propinas, se aguantó y siguió trabajando para pagar una deuda.

Casi todas las camaristas llevan de 21 a 30 años residiendo en las periferias de Cancún, que son las partes más marginadas, inseguras y menos dotadas de servicios urbanos (Oehmichen, 2010), aunque son los espacios factibles para pagar rentas más bajas o tener una propiedad, con o sin documentos oficiales. En el Mapa 3 aparecen las regiones de residencia de las camaristas. Las regiones son fraccionamientos urbanos que cuanto más cercanos estén a la zona hotelera es mayor su equipamiento e infraestructura, pero a la inversa empeoran dramáticamente las condiciones socioeconómicas, el trasporte y el equipamiento. Es ahí donde viven las camaristas; por este motivo ellas deben iniciar su jornada laboral muy temprano a fin de desplazarse -entre una hora u hora y media- a los sitios donde pueden acceder a un trasporte que las lleve a los hoteles en que trabajan. En ocasiones los hoteles ofrecen transporte a los trabajadores/as, pero de lo contrario, ellas han de gastar una sexta parte de su sueldo en ello.

Mapa 3. Regiones de residencia de las camaristas

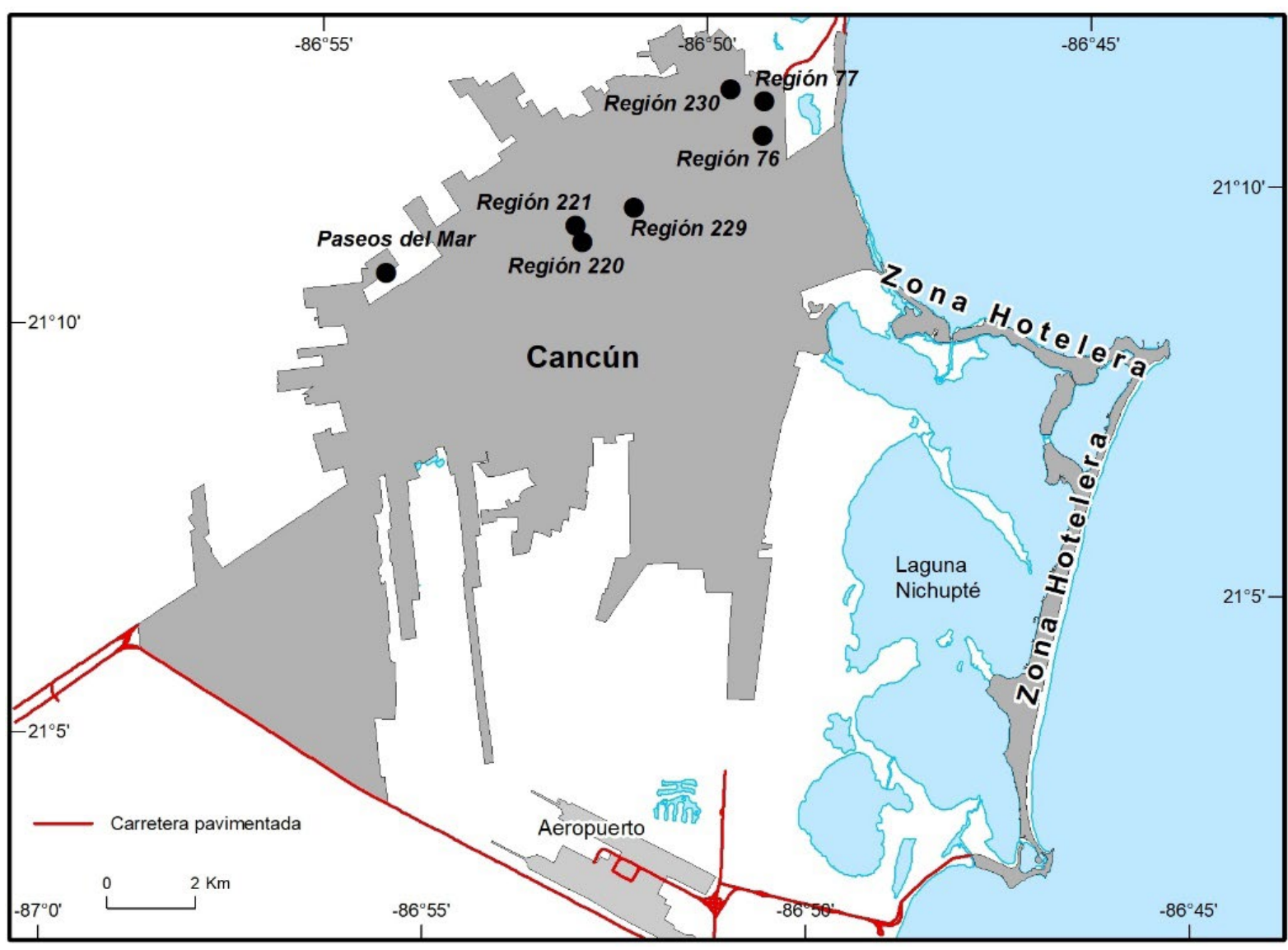

Fuente: Elaborado por María de Lourdes Godínez Calderón, 2019, con base en trabajo de campo 2018 y 2019.

Aunque son varias las razones que las camaristas dan sobre el motivo de haberse empleado en la limpieza de hoteles, predominan argumentos que tienen que ver con una necesidad desesperada, como el haber sido despedida de un anterior empleo, por ir buscando un 
mejor sueldo, para pagar deudas, etcétera; sólo dos dijeron que era por gusto. Normalmente, como migrantes con bajo nivel de instrucción escolar y bajos recursos, al buscar empleo deben hacerlo a pie, preguntando de hotel en hotel, en circunstancias muy difíciles, pues deben desplazarse desde el sitio en donde pernoctan (muy lejos de la zona hotelera): "yo cuando busqué trabajo me fui a la zona hotelera y me vine caminando hasta que lo encontré, porque no era sólo una persona, éramos varias... Y se tiene una que aguantar porque necesita dinero, porque necesitaba pagar mi deuda, porque para buscar otro trabajo, hay que salir a caminar" (Raquel). "He estado en otros hoteles buscando siempre el que me diera más dinero, más propina, porque mis niños eran pequeños y necesitaban pañales y leche" (Luis).

Todas las entrevistadas declararon haber trabajado en hoteles de Cancún, habiendo coincidido dos en el mismo hotel. Cinco de ellas llevan menos de diez años en su empresa y el resto más tiempo. Todas habían sido contratadas directamente por el hotel; casi todas trabajan o habían trabajado todo el año y la mayoría estuvo o estaba trabajando en hoteles de cinco estrellas -pertenecientes a cadenas hoteleras-, y sólo un par de ellas en hoteles administrados bajo otra categoría.

\subsection{Condiciones laborales y organizativas del hotel}

Existen dos modalidades laborales en los hoteles de Cancún: por una parte, está el personal de planta, que son aquellas trabajadoras estables y permanentes en la empresa y, por el otro, las que son contratadas por tiempo determinado. Sólo cuatro camaristas están con carácter permanente en la plantilla del hotel y llevan más de diez años trabajando en la empresa; al respecto, ellas argumentan que adquirieron esta condición después de varios años de contratos, y porque han sido percibidas por sus jefas como personas formales, puntuales y reconocidas como no conflictivas. La valoración de no conflictividad se apega a las expectativas que se tiene de las mujeres mexicanas, cuya construcción cultural de género también se asocia con la resignación al trabajo asignado, en tanto que se ven forzadas a mantener su empleo para cubrir, al mismo tiempo, el papel de madre-esposas y a la manutención de sus hijos/as, lo cual les suele colocar en una posición desfavorable frente a las circunstancias de los hombres (Pérez-Gil y Ravelo, 2004).

El resto de las camaristas había estado trabajando por contrato, renovado cada uno, dos, tres o cuatro meses, en función de cada empresa. A fin de que no generen antigüedad, les ofrecen algunos días de baja o de descanso y las vuelven a contratar, de modo que no generan derechos. El hecho de que las camaristas sigan aceptando que se les contrate, no es una garantía para que en un futuro logren su condición de ser personal fijo. Por ejemplo, dos de ellas llevan entre tres y cinco años en el hotel y sin embargo, no lo han logrado: "ahí sólo dan contrato cada mes, es muy difícil que te den planta hoy en día en un hotel, quién sabe por qué, pero ya no les conviene dar planta" (Eli).

Todas las camaristas tienen seguro social y según qué empresas, podrían contar con aguinaldo y vales de comida, lo que implica que las camaristas vayan buscando aquellos hoteles que proporcionen las mayores ventajas laborales. 
Oficialmente trabajan ocho horas al día, de las 8:00 a las 16 horas, no obstante, todas las camaristas entrevistadas comentaron que sólo pueden salir del hotel cuando concluyen con todo el trabajo asignado; por regla general deben limpiar doce habitaciones, pero en función de sus cálculos y de las exigencias de sus jefas, esa labor siempre les lleva hasta una hora más de trabajo no pagado: "entro a las 8 de la mañana y termino a las 4:00 o 5:00 de la tarde, es muy raro que termine a las 4:00 porque no se termina, el trabajo es exigente" (Lupe).

Cuando alguna camarista falta o al llegar la temporada alta, el mismo número de camaristas contratadas son las que deben hacer todo el trabajo. Por lo general, ellas toman esta responsabilidad extra, pues les supone un poco más de dinero o una recompensa en tiempo (María). Aunque por una parte esto pueda ser visto como benéfico en términos económicos, por la otra, implica el sacrificar tiempos de convivencia familiar, tal y como expresan algunas camaristas, pues llegan muy tarde a sus hogares, que como se ha visto en el Mapa 3, están muy alejados de la zona hotelera.

El tiempo estimado para la limpieza depende de si la habitación está ocupada o los clientes ya la desocuparon; para la primera se requiere una media hora y para la segunda una hora, aunque esto varía según lo sucia y desordenada que haya quedado. Para que las camaristas alcancen a completar su trabajo en un tiempo adecuado, tratan de compensar el tiempo empleado en una habitación desocupada con el de una ocupada. Igualmente, la habilidad de cada una de ellas es clave para ir más rápido o más lento: "te tiene que dar tiempo, ahí depende ya tu habilidad... Es como tú te organices, que tú sepas a qué es lo que vas" (María). Esta estrategia de trabajo, de compensar unas habitaciones con otras, suele ser insuficiente en las temporadas altas y por ello suelen sacrificar su almuerzo: "aunque tuviera hambre, seguía trabajando y hasta que no lo has terminado no bajabas a comer" (Carmen).

Las camaristas entrevistadas dijeron que disponen de un día de descanso semanal, pero cuando la ocupación se eleva, ellas pueden optar por trabajarlo o no; casi todas ellas comentan que tienen la flexibilidad de intercambiar con sus compañeras el día de descanso, sin embargo, en otras ocasiones, solicitar un determinado día por un evento personal, depende del criterio arbitrario de sus jefes: "para pedir ese tipo de favores hay que pensar qué día se lo pedimos o qué día está de buena" (María). De esta manera, mostrarse proclives a aceptar trabajar cuando la empresa lo requiere, puede generar más empatía en unas y una relación más ríspida con otras, situación que es utilizada como una forma de control por los o las jefas.

Cuando baja la ocupación, a las trabajadoras de contrato se les "asignan" días de permiso sin sueldo, lo que supone someterlas a una alta precariedad laboral y económica y ello no se compensa con la fidelidad que la empresa demanda de ellas en temporadas altas: "si tú estás bajo contrato te daban tus días, pero no pagados. Yo tenía que reunir 1,000 dólares para que cuando bajara la ocupación, yo tuviera mi guardadito, porque si no tenía, con qué iba yo a comer" (Luis).

El salario percibido por las camaristas es el llamado mínimo, entre los 61 y los 85 euros a la quincena, aunque a esto se suman las propinas del sindicato, de los huéspedes y, ocasionalmente, los vales de despensa: "nosotras las camaristas ganamos 1,600 quincenales [pesos mexicanos, equivalentes a 76 euros], pero como tú vayas atendiendo a tu huésped..., ellos 
ven cómo limpias, cómo les pone los zapatos, que quede el cuarto oloroso..., te van conociendo, tienen tu tarjeta de camarista y te dan 10 o 5 dólares y ahí nosotros nos recuperamos. Por eso a las camaristas no nos importa cómo es el sueldo, también cada 15 días recibimos 3,000 [pesos mexicanos, equivalentes a 142 euros] en propina por el sindicato, por eso no nos importa ganar lo mínimo" (María).

A pesar de las jornadas extenuantes de trabajo, las paupérrimas condiciones laborales en el sur y sureste de México hacen que muchas camaristas valoren positivamente su salario, pues los hoteles les pueden proporcionar el almuerzo y el transporte hasta algún punto determinado de su ruta; asimismo, los días festivos se suelen pagar al doble, y los huéspedes pueden dejar en las habitaciones mercancías como alimentos, productos de higiene personal, que son de gran utilidad para las trabajadoras: "de camarista recibes el salario del hotel y las propinas, por eso mucha gente quería ser camarista" (Pepa). Todas coinciden que el sueldo es el mismo todos los meses, haya una ocupación alta o baja de turistas, en todo caso, lo único que varía es la propina.

Así, la propina del cliente adquiere un peso central para las camaristas, no sólo en términos de su sueldo, sino porque les significa una recompensa, el reconocimiento, la validación y valoración de su trabajo: "hay huéspedes que te recompensan con propina y te sientes satisfecho, uno cuando entraba decía, gracias a Dios, me tomaron en cuenta, ahí te reconocen tu trabajo realmente" (Luis). Es notorio observar que la propina está presente en el discurso de las camaristas (Gráfica 1), pues prácticamente se conecta con su vida laboral y con los efectos que tiene más allá de su trabajo y, sin duda alguna, de no existir la propina como elemento compensatorio del salario paupérrimo, la percepción de su trabajo sería completamente negativa.

Incluso, es común observar que las alusiones que las camaristas hacen al sindicato se asocian, más que a la lucha por sus derechos, al interés en las propinas que de este reciben, de hecho, la conexión del sindicato como agrupación de lucha por sus derechos, más bien tiene un cariz negativo: "tenemos sindicato de apoyo para el hotel, pero en muchas ocasiones el hotel lo compra, así que no se puede hacer nada" (Lupe). Sólo dos camaristas refieren el buen funcionamiento de esta organización.

A pesar de que las camaristas consideran que el sueldo está bien, tres de ellas tuvieron que renunciar al trabajo porque no podían conciliar su trabajo con la vida familiar: "el sueldo es bueno, aunque es mucho la matanza, sobre todo en la temporada alta, porque cuando están cortos de camarista te pueden dar 16 y hasta 17 cuartos y sales a las 7:30 o 8:00 de la noche, pero descuidas lo que es tu hogar, tu hija en mi caso" (Carmen). A pesar de la explotación a la que están sujetas las camaristas, Ferguson (2010) refleja que estas mujeres suelen valorar positivamente sus empleos, aunque se infiere que tal sobrevaloración es resultado de las condiciones paupérrimas de otro tipo de trabajos, más que a empleos remunerados con equidad para las partes implicadas.

Las camaristas, tanto las que están fijas como las que están por contrato, no suelen tener problemas o casi ninguna consecuencia por solicitar uno o dos días por enfermedad, pero si se solicita una incapacidad -por algún accidente laboral o una dolencia complicada-, el proceso se dificulta por parte de las compañías privadas de salud: "vamos a suponer que 
me he caído en el hotel, pero cuando vamos al seguro nos preguntan, ¿cómo se cayó?, ¿quién le vio?, ¿a dónde estaba? Nos piden miles de papeles y tienes que decir siempre las mismas palabras... Porque o si no, no te dan la incapacidad" (María).

\subsection{Los jefes, la salud y la percepción de su labor como camaristas}

Todas las camaristas expresaron haber sufrido maltratos por parte de su jefe o jefa inmediata, como gritos, uso de groserías, humillaciones, entre otros. Al respecto María dice que "hay de malas maneras, cómo te hablan, te gritan... Nos hemos encontrado con gente así, son muy prepotentes. Yo pienso que hay jefes buenos y jefes de mal carácter, pero me digo, así es el trabajo", luego Eva señala que los jefes "son muy exigentes porque a ellos también les exigen un buen trabajo". Se reconoce que hay cierto abuso, el cual ha sido normalizado por ellas, pues asumen que son inherentes al propio trabajo.

Por otra parte, Lupe dice que "con esta ama de llaves ya van seis; han sido muy mal habladas, tratan mal; cuando llega la encargada superior de las camaristas, nos hacen desprender el contacto de luz y fregar los ventiladores... También tenemos una escalerita para eso, si entra ella y no limpiaste el ventilador te regresa a limpiarlo, -señora, que tengo miedo a caerme-, pues tienes que hacerlo... A veces te atosigan de que tú fuiste, tú fuiste quien robaste y despiden a gente inocente y los corren y los boletinan" (es decir, una notificación que se envían entre los hoteles de Cancún para que le cierren las puertas a nivel laboral). Si bien los maltratos directos son frecuentes, los indirectos son mayores y mucho más efectivos en la explotación, pues con la amenaza a ser boletinadas prefieren soportar excesos.

A diferencia de estudios realizados sobre las camaristas de Estados Unidos o España, en los que sí reportan problemas frecuentes de salud (Scherzer, Rugulies, y Krause, 2005; Premji y Krause, 2010; Hsieh et al., 2014, 2016; Cañada, 2015), es particularmente notorio que en Cancún esto no es percibido de manera alarmante, por ejemplo, Carmen comentó que "nos proporcionaban fajas, todas las camaristas tienen que estar fajadas al momento de agacharte, y nos daban cursos sobre cómo teníamos que agacharnos. También recibíamos cursos para el estrés". Si bien es verdad que la carga de trabajo que tienen las camareras de Cancún es menor que las de España -por ejemplo-, también es cierto que su permanencia en este trabajo no es tan larga como en otros países y además suelen ser más jóvenes, por ello tal vez no tengan patologías notorias por movimientos repetitivos, pero lo que sí es comentado con frecuencia es que tienen un estrés acentuado, particularmente cuando se acerca la hora de salida y notan que no acabarán su labor.

Una vez que las camaristas han aprendido las técnicas de limpieza y cómo vencer los obstáculos que limitan su rapidez en el trabajo, la mayoría suele considerarlo llevadero, pero esto puede tener una valoración diferente cuando se asocia con su salario; por ejemplo, cinco camaristas consideran que el salario es muy bajo para las tareas que desarrollan y el tiempo que les demandan, mientras que las otras cinco creen que es justo el salario, pero siempre que existan las propinas. También es interesante observar que el trabajo de camarista ha sido importante para empoderarse genéricamente en la sociedad: "mi trabajo es muy importante 
para mí y me da vida" (Eli). En su condición de marginación, el tener un trabajo de camarista les dota de cierta independencia con la que pueden lidiar con la opresión social en que viven.

El valor que este trabajo les otorga, en términos de lograr un mayor empoderamiento social, les hace pensar a la mayoría que sí les gustaría jubilarse en este empleo porque perciben que es difícil conseguir algo mejor en sus circunstancias. De hecho, las que habían dejado su empleo lo hicieron porque su familia demandaba de su tiempo. Pero también existe la duda de que, por lo pesado de sus labores, tal vez no puedan lograr mantenerse en la limpieza de hoteles: "a ver si aguanto..." (Lupe); "quién sabe, pueden pasar muchas cosas, te puedes caer, te puedes lastimar, te pueden echar..." (María).

Las camaristas tienen cierta conciencia de que su trabajo no se realiza con justicia para las partes involucradas. Por ejemplo, ante la pregunta de ¿quiénes se benefician con su trabajo?, las respuestas se dirigen sobre todo al hotel, el dueño o los jefes, y para otras pocas, hacia ellas mismas y/o sus hijos/as. Al mismo tiempo, hay una percepción diferenciada en cuanto a la mejora o empeoramiento de sus condiciones laborales a lo largo del tiempo, cinco piensan que en realidad todo sigue igual, tres que es peor y dos que es mejor. Finalmente, uno de los asuntos que parece ser favorecedor para percibir más positivamente este trabajo tan competitivo es el compañerismo, sin embargo, este suele situarse en el plano de la conveniencia: "nos tenemos que apoyar, aunque no nos caigamos bien, esa compañera va atrasada y le ayudas, porque mañana puedo yo necesitar tal vez de ella" (María).

\subsection{Relación huésped-camarista}

Todas las trabajadoras hablaron, en general, del buen trato que han recibido de los turistas, de hecho, dos enfatizaron que es fundamental tener buen trato con ellos si se desea mejorar la propina, aunque también las dificultades están a la orden del día. La mayoría de las entrevistadas aludieron a que los turistas suelen acusarlas de robo de dinero y objetos de valor: "Hay muchos casos en los que el huésped dice que entraron a robar, luego hacen la lectura de chapas y aparece que la camarista hizo su limpieza a las 9 de la mañana, y él reportó a las 4 de la tarde un robo..., porque luego quieren una compensación o una noche más ..., y a veces no es cierto que le robaron nada" (Toña).

Cancún, a nivel mundial, es famoso por el arribo de una gran cantidad de turistas adolescentes o personas muy jóvenes que llegan en grupos grandes, denominados spring breakers; como es sabido, sus formas de diversión están muy ligadas con el consumo de alcohol y otro tipo de drogas, lo que eleva la posibilidad de que cometan varios excesos, y ello redunda directa o indirectamente en problemas que se les acumulan a las camaristas: "Los turistas de spring break son muy destructivos, rompen la tele, la puerta, están bien locos... Este tipo de persona se hace pis en cualquier lado, vomitan encima de la cama, pero nosotros tenemos que checar y reportar, le avisamos a la supervisora que llega y le hace su foto para mandarlo luego a dirección, a veces lo niegan, aunque lo hayan hecho ellos" (Lupe).

Varias camaristas refirieron haber tenido alusiones sexuales de turistas hombres y mujeres, ante lo cual se han sentido desprotegidas, pues los hoteles tratan de ocultar este tipo de hechos: "sí me ha pasado en alguna ocasión que algún hombre o mujer me ha hecho señas 
como para tener relaciones y cuando me ha pasado eso, he salido corriendo de la habitación" (Eli). Por su parte, Luis dijo que en el periodo de los spring breakers, escuchó que una camarista de su mismo piso gritó y acudió a la habitación, al llegar vio que los huéspedes le estaban tapando la boca para violarla: "El hotel no te va a dar la razón a ti, el hotel se pone de parte del huésped, no violaron a la chava ... Se lo dijo al ama de llaves, hicieron investigación, pero los chavos dijeron que no, ellos pudieron haberla acusado porque eran cuatro personas, entonces la chava se quedó callada y sólo me contó a mí. Con el turno de tarde, cuando los huéspedes llegan de la playa y la camarista tiene que entrar, pueden pasar muchas cosas".

\section{CONCLUSIONES}

La aproximación a las condiciones laborales de las camaristas y a la percepción que ellas mismas tiene de sus actividades se hizo a partir de diez trabajadoras de hoteles de Cancún; se eligió esta ciudad por ser el principal destino litoral mexicano, prototipo de la reproducción de la fuerza laboral turística (Marín, 2012). Con el planteamiento de una perspectiva cultural de género, se buscó no sólo dar voz a las camaristas, poco estudiadas a pesar de su importancia en los destinos turísticos, sino porque reflejan la construcción del género como una condición de desigualdad que reproduce su papel de cuidadoras del hogar a la limpieza de habitaciones (Díaz, Verján y Castrejón, 2014). La consideración investigativa del género en el turismo (Sigüenza, 2011), no sólo tiene la intención de dar notoriedad a hombres y mujeres, sino modificar la inequidad y subordinación de unas sobre otros.

Los resultados de este estudio concuerdan con los ejemplos de vulnerabilidad encontrados por Albarracín y Castellanos (2013), siendo estas limpiadoras en Cancún mujeres inmigrantes residentes en esta localidad desde hace más de 20 años y que sólo tienen como nivel máximo de estudios el primario. No se encontraron mujeres empleadas de manera externalizada o por outsourcing, aunque sus condiciones con los hoteles son desventajosas, la mayoría tienen un contrato renovado en periodos cortos, a fin de que no generen derechos y para sustituir con facilidad a las camaristas menos eficientes (a criterio de las o los jefes inmediatos). Si bien todas tienen seguro social, sólo las fijas tienen vacaciones, porque las de contrato no reciben ninguna paga hasta la renovación de uno nuevo, de modo que tienen "vacaciones" forzadas que deben subvencionarse con sus propios medios y estar disponibles cuando el hotel les llame (Seifert y Messing, 2006; Cañada, 2016, 2018 y 2019).

Aunque las camaristas trabajan ocho horas al día durante seis días a la semana, cuando el hotel les demanda quedarse más tiempo para finalizar el trabajo asignado o el que subrepticiamente surge, deben hacerlo sin paga extra; así, pueden llegar más tarde a casa, lo que desfavorece la conciliación familiar, especialmente en la temporada alta, cuando podrían limpiar más de las habitaciones que acostumbran a hacer (McNamara, et al., 2011; Cañada, 2016). No existe la figura de "horas extras", en todo caso, se pagan las habitaciones extras en dinero o en tiempo. Pese a todo lo anterior, suelen valorar positivamente su trabajo (Ferguson, 2010), pues la propina (procedente del turista o del sindicato) tiene un papel preponderante, por ser un reconocimiento y validación de su trabajo. Por otro lado, el sindicato es una institución que provee un dinero adicional al sueldo que perciben y no supone un organismo que resuelva los problemas laborales. 
Otro tipo de problemas que enfrentan, asociado también con su condición de género, es el hecho de tener que aceptar la carga laboral y horarios que se les impongan pues, aunque pueden negarse a ello, están bajo la amenaza tácita de no ser recontratadas; al mismo tiempo, los abusos, malas maneras y humillaciones de sus jefas o jefes inciden en tensiones laborales, que deben aguantar, pues sus superiores saben de su vulnerabilidad. Las entrevistadas consideraron que el trabajo no les afecta en su salud física, es decir, no asociaron sus enfermedades con su condición laboral, asunto sobre este tema se tendrá que investigar más en el futuro, desde una perspectiva de medicina del trabajo. Otra situación de tensión que viven es el hecho de que pueden ser acusadas de robo, ante lo cual son particularmente vulnerables, pues las quejas e imputaciones de los turistas tienen mayor valor que su palabra. Además, también está presente la posibilidad del acoso sexual, pues en un momento dado, estar expuestas a un espacio privado las vulnera notablemente.

Pese a estas problemáticas, su trabajo como camareras tiene un valor que no sólo radica en el ingreso que obtienen, sino en el hecho de que les permite un empoderamiento en la sociedad; para ellas, provenientes de vecindarios paupérrimos y lejanos, el poder mantenerse por un tiempo en un entorno que les da trabajo, comida y les ofrece la oportunidad de interactuar y desarrollar habilidades comunicativas multiculturales, les proporciona una mayor autonomía y confianza en sí mismas.

\section{BIBLIOGRAFÍA}

Albarracín, D. y Castellanos, M. L. (2013). Las trabajadoras de los establecimientos hoteleros. Trayectorias en el túnel silencioso de la subordinación. Sociología del trabajo, 77, 27-45.

Araiza, A. (2004). Empoderamiento femenino: el caso de la comunidad zapatista de Roberto Barrios. Feminismo/s, 3, 135-148.

Arroyo, L.; López, A.; Segrado, R. G.; Serrano, R. y Frausto, O. (2015). Diferencias socio-territoriales en Tulum: una ciudad organizada a partir del turismo masivo litoral. Cultur, 9(2).

Caamaño, E. (2010). Mujer y trabajo: origen y ocaso del modelo del padre proveedor y la madre cuidadora. Revista de Derecho, 34, 179-209.

Cáceres, R. y Valcuende, J. M. (2014). Globalización y diversidad sexual, gays y mariquitas en Andalucía. Gazeta de antropología, 30(3).

Cañada, E. (2015). Las que limpian los hoteles. Historias ocultas de precariedad laboral. Barcelona: Icaria Editorial.

Cañada, E. (2016). Externalización del trabajo en hoteles. Impactos en los departamentos de pisos. Barcelona: Alba Sud Editorial.

Cañada, E. (2018). Intensificación del trabajo en los hoteles: La percepción de las Kellys. Iglesia Viva, 275, julio-septiembre, 117-126.

Cañada, E. (2019). El trabajo de las camareras de piso: un estado de la cuestión. Papers de turismo, 62, 58-75.

Castillo, O. y Villar, A. J. (2011). La conformación del espacio urbano de Cancún: una aproximación al estudio de la segregación socio-espacial. Quivera, 13(1), 83-101. 
Asociación las Kellys (2017). Las camareras de piso se organizan contra la precariedad en el sector hostelero. Varias Kellys de Barcelona, Benidorm, Fuerteventura, Lanzarote y Madrid. Libre Pensamiento, 91, 59-64.

CONAPO (Consejo Nacional de Población) (2016). Índice de marginación por entidad federativa y municipio, 2015. Gobierno de México. Disponible en: https://www.gob.mx/conapo/ documentos/indice-de-marginacion-por-entidad-federativa-y-municipio-2015.

Cotelo, S., Herrera, M. E. y Alarcón, A. D. (2016). Enfoque de género y políticas públicas. Una propuesta para el turismo en el destino Jardines del Rey - Cuba. Rev. Turismo y Sociedad, (18), 79-97.

Díaz, I. A.; Verján, R. y Castrejón, B. E. (2014). Estereotipos de género y turismo: análisis cualitativo del "suelo pegajoso" en hoteles de 4 y 5 estrellas en Tijuana (México). TuryDes, Revista Turismo y Desarrollo local, 7(17).

Díaz, I. A. (2013). Mujeres y mercado de trabajo del turismo alternativo en Veracruz. Economía. Sociedad y Territorio, 13, [en linea]. [Fecha de consulta: 9 de abril de 2019]. Disponible

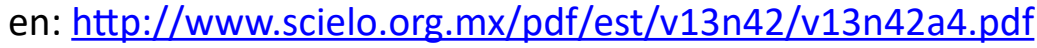

Escudero, K. Y.; Serrano, R.; Segrado, R.; Serrano, C. y López, E. (2017). Empoderamiento de la mujer en establecimientos de hospedaje en Metepec Estado de México. Gran Tour: Revista de Investigaciones Turísticas, 15, 3-25.

Ferguson, L. (2010). Turismo, igualdad de género y empoderamiento de las mujeres en Centroamérica. Papeles de relaciones eco sociales y cambio global, 111, 123-133.

Ferguson, L. (2011). Promoting gender equality and empowering women. Tourism and the third millennium development goal. Current Issues in Tourism, 14(3), 235-249.

Ferguson, L. \& Moreno D. (2015). Gender and sustainable tourism: reflections on theory and practice. Journal of Sustainable Tourism, 23(3), 401-416.

Fernández, M. J. y Martínez, L. A. (2010). Participación de las mujeres en las empresas turísticas privadas y comunitarias de Bahías de Huatulco, México. ¿Hacia un cambio en el rol de género? Cuadernos de Turismo, 26, 129-151.

Garazi, D. (2014). Trayectorias laborales, trabajo estacional e identidades: Las mucamas de hotel de Mar del Plata (1960-1980). VIII Jornadas de Sociología de la UNLP, 3 al 5 de diciembre de 2014, Ensenada, Argentina. En Memoria Académica, 1-19.

García de Fuentes, A. (1979) Cancún: Turismo y subdesarrollo regional. México: UNAM, Instituto de Geografía.

García, S.; Galante, F. y Poveda, V. (2018). El techo de cristal en la industria hotelera de Tenerife (Islas Canarias): el acceso de las mujeres al liderazgo en el sector. Revista de Turismo y Patrimonio Cultural, PASOS, 16(4), 1105-1117.

Guil, A. (2008). Mujeres y ciencia: techos de cristal. EccoS Revista Científica, 10(1), 213-232.

Gutiérrez, L. E. y Limas, M. (2008). Incorporación de la mujer al mercado de trabajo y desarroIlo regional en Chihuahua. Estudios Fronterizos, 9(18), 39-70.

Heather L. J. (2018). Tourism and gendered hosts and guests. Tourism Review, 74(5), 10381046. .

Hsieh, Y. Apostolopoulos, Y. \& Sönmez, S. (2013). The world at work: hotel cleaners. Occupational and Environmental Medicine, 70(5), 360-364. 
Hsieh, Y., Apostolopoulos, Y., Hatzudis, K. \& Sönmez, S. (2014). Occupational Exposures and Health Outcomes Among Latina Hotel Cleaners. Hispanic Health Care International, 12(1), 6-15.

Hsieh, Y. C., Apostolopoulos, Y. \& Sönmez, S. (2016). Work Conditions and Health and WellBeing of Latina Hotel Housekeepers. Journal of Immigrant and Minority Health, 18(3), 568-581.

Hubacek, K., Prell, C, Reed, M., Boys, D., Bonn, A. \& Dean, C. (2006). Using stakeholder and social network analysis to support participatory processes. International Journal of Biodiversity Science \& Management, 2(3), 249-252.

Huete, R.; Brotons, M. y Sigüenza, M. C. (2016). La desigualdad entre las mujeres y hombres en el sector hostelero español. Estudios y Perspectivas en Turismo, 25(1), 73-87.

Hunter, P. \& Watson, D. (2006). Service unseen: The hotel room attendant at work. International Journal of Hospitality Management, 25(2), 297-312.

Kensbock, S.; Jennings, G; Bailey, J. \& Patiar, A. (2013). "The lowest rung": Women room attendants' perceptions of five star hotels' operational hierarchies'. International Journal of Hospitality Management, 35, 360-368.

Lamas, M. (2000). Diferencias de sexo, género y diferencia sexual. Cuicuilco, $7(18)$.

Li, L. \& Wang, R. (2001). Female managers in Asian hotels: profile and career challenges. International Journal of Contemporary Hospitality Management, 13(4), 189-196.

Liladrie, S. (2010). "Do not disturb/please clean room": hotel housekeepers in Greater Toronto. Race \& Class, 52(1), 57-69.

Lockwood, A. \& Guerrier, Y. (1989). Flexible Working in the Hospitality Industry: Current Strategies and Future Potential. International Journal of Contemporary Hospitality Management, 1(1) 11-17.

López, A.; Cukier, J. \& Sánchez, A. (2006). Segregation of Tourist Space in Los Cabos, Mexico. Tourism Geographies, 8(4), 359-379.

Marín, G. (2012). Los tristes trópicos del turismo en México: industria, reflexividad y otras ficciones en G. Marín; A. García de Fuentes, A. y M. Daltabuit (Coords.). Turismo, globalización y sociedades locales en la península de Yucatán, México (pp. 17-43). El Sauzal, Tenerife (España): Colección PASOS edita nำ, PASOS, Revista de turismo y patrimonio cultural.

Martín, A. (2012). Antropología del género. Culturas, mitos y estereotipos sexuales. España: Ediciones Cátedra (Grupo Anaya).

McDowell, L. (2010). Interviewing: Fear and liking in the field. En D. Delyser; S. Herbert; S. Aitken; M. Crang and L. McDowell (Eds.), The SAGE handbook of qualitative geography. London: SAGE Publications Ltd.

McKenzie, K. (2007). Belizean women and tourism work. ¿Opportunity or impediment? Annals of Tourism Research, 34(2), 477-496.

McNamara, M.; Bohle, P. \& Quinlan, M. (2011). Precarious employment, working hours, worklife conflict and health in hotel work. Applied Ergonomics, 42(2), 225-232.

Medeiros de Araujo, L., \& Bramwell, Bill (1999). Stakeholder assessment and collaborative tourism planning: the case of Brazil's Costa Dourada project. Journal of Sustainable Tourism, 7, 356-378. 
Mogensen, F., Mayer, M., Breiting, S. y Varga, A. (2007). Educació per al desenvolupament sostenible: tendències, divergències i criteris de qualitat. Barcelona: Editorial Graó.

Moreno, D. y Cañada, E. (2018). Dimensiones de género en el trabajo turístico. Serie informes en contraste, 4. Barcelona: Alba Sud Editorial.

Munshi, I. (2006). Tourism processes and gender Relations: Issues for exploration and intervention. Economic and Political Weekly, 41(42), 4461-4468.

Oehmichen, C. (2010). Cancún: la polarización social como paradigma en un México Resort. Alteridades, 20(40), 23-34.

Onsøyen, L. E., Mykletun, R. J., \& Steiro, T. J. (2009). Silenced and invisible: The workexperience of room-attendants in Norwegian hotels. Scandinavian Journal of Hospitality and Tourism, 9(1), 81-102.

Oxfam Canadá Report (2017). Tourism's dity secret: the exploitation of hotel housekeepers. Disponible en: https://www.oxfam.ca/publication/tourisms-dirty-secretthe-exploitation-of-hotel-housekeepers/

Pacheco, L. (2012). La igualdad de oportunidades y el derecho al trabajo de la mujer: un esfuerzo internacional de protección social. Revista del Instituto de Ciencias Jurídicas de Puebla A.C., 6(29), 108-129.

Pérez-Gil, S. E., \& Ravelo, P. (2004). Voces disidentes. Debates contemporáneos en los estudios de género en México. México: Porrúa-CIESAS.

Premji, S. \& Krause, N. (2010). Disparities by ethnicity, language, and immigrant status in occupational health experiences among Las Vegas hotel room cleaners. American Journal of Industrial Medicine, 53(10), 960-975.

Puech, I. (2007). Cleaning time, protest time: employment and working conditions for hotel maids. Sociologie du Travail, 49(1), 50-65.

Purcell, K. (1996). The relationship between career and job opportunities: women's employment in the hospitality industry as a microcosm of women's employment, Women in Management Review, 11 (5), 17-24.

Queirolo, G. (2004). El trabajo femenino en la ciudad de Buenos Aires (1890-1940): una revisión historiográfica, Temas de Mujeres, 1(1), 55-87.

Real-Pérez, G. L.; García-Dihigo, J. A.; Piloto-Fleitas, N.; Regueira-Lezcano, M. D. (2011). Diagnóstico ergonómico en las camareras de piso del sector hotelero. Caso Varadero, Cuba. Ingeniería Industrial, 32(3), 171-178.

Reed, M. S., Fraser, E. D. G., \& Dougill, A. J. (2006). An adaptive learning process for developing and applying sustainability indicators with local communities. Ecological economic, 59(4), 406-418.

Sabariego-Puig, Marta, Vilà-Baños, Ruth, \& Sandín-Esteban, Maria- Paz. (2014). El análisis cualitativo de datos con ATLAS.ti. REIRE, Revista d'Innovació I Recerca En Educació, 7(2), 119-133.

Scherzer, T., Rugulies, R., and Krause, N. (2005). Work-related pain and injury and barriers to workers' compensation among Las Vegas hotel room cleaners. American Journal of Public Health, 95(3), 483-488.

SEDETUR (Secretaría de Turismo) (2017). Cancún: el 80 destino turístico más popular del mundo: Expedia. Quintana Roo, Gobierno de México. Disponible en: https://qroo.gob. $\mathrm{mx} /$ sedetur/cancun-8o-destino-turistico-mas-popular-del-mundo-expedia. 
Segovia, M. (2013). Mujer y techo de cristal en el sector turístico. Madrid: Estudios e Investigaciones del Instituto de la Mujer y para la igualdad de oportunidades.

Seifert, A. \& Messing, K. (2006). Cleaning up after globalization: An ergonomic analysis of work activity of hotel cleaners. Antipode, 38(3), 557-578.

Serrano, R.; Mendoza, R.; Palmas, D.; Zarza, P. y Osorio, M. (2017). Participación laboral de la mujer en establecimientos de hospedaje. Caso posadas familiares en Tonatico, México. Revista Rosa dos Ventos - Turismo e Hospitalidade, 9 (3), 318-337.

Sigüenza, M.C. (2011). La mujer en el subsector del alojamiento. El caso de la Costa Blanca (Alicante, España). Investigaciones Turísticas, 2, 102-119.

Sinclair, M. T. (1997). Issues and theories of gender and work in tourism. En M. T. Sinclair (ed.), Gender, Work and Tourism (pp. 1-14). Londres: Routledge.

Sparrer, M. (2003). Género y turismo rural. El ejemplo de la Costa Coruñesa. Cuadernos de Turismo, 11, 181-197.

Torns, T. y Recio, C. (2012). La desigualdad de género en el mercado de trabajo: entre la continuidad y la transformación. Revista Economía Crítica, 14 (2), 178-2002.

Triguero, N. (2017). CCOO espera que Trabajo sancione a los 44 hoteles que ha denunciado por externalizar el servicio de camareras de piso sin respetar el convenio provincial de hostelería. Diario Sur. Disponible en: https://www.diariosur.es/malaga-capital/camareras-20170907222733-nt.html

Vizcaino, P., Serrano-Barquín, R., Cruz G. y Pastor-Alfonso M. J. (2016). Teorías y métodos en la investigación sobre turismo, género y mujeres en Iberoamérica: un análisis bibliográfico. Cuadernos de Turismo, 38, 485-501.

Zamora, J., Barril, M. E. y Benavides, E. (2010). Identificación de las barreras endógenas percibidas al desarrollo turístico de sol y playa. Un caso comparativo en la costa central de Chile. Estudios y Perspectivas en Turismo, 19(2), 221-240.

\section{CONTRIBUCIONES DE LAS/LOS AUTORES/RES}

La autora Antonia Balbuena Vázquez ha contribuido a la concepción original del trabajo, así como a la elaboración, realización, interpretación y redacción de las entrevistas, por tanto, ha estado a cargo de la metodología, los resultados y la conclusión del artículo.

El autor Álvaro López López ha aportado la redacción del marco teórico, la introducción, la revisión crítica del contenido y la revisión de la redacción del artículo finalizado.

Ambos autores aprobaron la versión final a publicar.

\section{AGRADECIMIENTOS}

Este artículo ha sido posible gracias al apoyo del Programa de Becas Postdoctorales de la Dirección General de Asuntos del Personal Académico (DGAPA), Universidad Nacional Autónoma de México (UNAM).

Las ilustraciones cartográficas han sido diseñadas y construidas por María de Lourdes Godínez Calderón. 